\title{
Evaluation of associated risk factors of near miss obstetrics cases at B.P. Koirala Institute of Health Sciences, Dharan, Nepal
}

\author{
Madan Khadka*, Dhruba Kumar Uprety, Rubina Rai
}

Department of Obstetrics and Gynecology, B. P. Koirala Institute of Health Sciences, Dharan, Sunsari, Nepal

Received: 16 December 2017

Accepted: 22 December 2017

*Correspondence:

Dr. Madan Khadka,

E-mail:khadka4all@gmail.com

Copyright: (C) the author(s), publisher and licensee Medip Academy. This is an open-access article distributed under the terms of the Creative Commons Attribution Non-Commercial License, which permits unrestricted non-commercial use, distribution, and reproduction in any medium, provided the original work is properly cited.

\begin{abstract}
Background: In 2011, around 273,465 women died worldwide during pregnancy, childbirth or within 42 days after childbirth. Near-miss is recognized as the predictor of level of care and maternal death. The objective of the study was to evaluate the associated risk factors of near miss obstetric cases.

Methods: A prospective observational study was done from August 1, 2014 to July 30, 2015 in Department of Obstetrics and Gynecology at BPKIHS hospital, tertiary care hospital in Eastern Nepal, Dharan. Case eligible by 5 factor scoring system and WHO near miss criteria were evaluated. Risk factors included severe hemorrhage, hypertensive disorders, complication of abortion, ruptured uterus, medical/surgical condition and sepsis.

Results: A total of 9,727 delivery were attended during the study period from August 2014 to July 2014. There were $6307(71.5 \%)$ vaginal delivery and 2777 (28.5\%) caesarean section and 181 perinatal death with total of 9,546 livebirth. 162 near miss and 16 maternal death occurred during the study. Maternal near miss rate of 16.6 per 1000 live birth, Women with life-threatening conditions of 172, Severe maternal outcome ratio of 18.64, Maternal nearmiss: mortality ratio: 10.1:1, Mortality index: $8.98 \%$. Risk factors were obstetric hemorrhage $27.8 \%$, abortion/ectopic $27.2 \%$, eclampsia $16 \%$, medical/surgical condition $14.8 \%$, sepsis $13.6 \%$, severe preeclamsia $11.1 \%$, ruptured uterus $3.1 \%$, and molar pregnancy $1.9 \%$ and cardiovascular and coagulation dysfunction as a major life-threatening condition and sepsis $(25 \%)$ was the major cause of mortality.

Conclusions: Haemorrhage and hypertensive disorders are the leading causes of near miss event. Evaluation of associated risk factor can be potential tool for reduction of maternal morbity and mortality.
\end{abstract}

Keywords: Abortion, Eclampsia, Five factor scoring system, Hemorrhage, Maternal mortality, Near miss

\section{INTRODUCTION}

Worldwide, more than half a million women between age 15-49 die each year from the complication of pregnancy and childbirth. ${ }^{1}$ Near misses have emerged as a useful complement to the investigation of maternal deaths. ${ }^{2}$

Near miss is defined as "A woman who nearly died but survived a complication that occurred during pregnancy, childbirth, or within 42 days of termination pregnancy. ${ }^{2,3}$ The patient survived either by chance or because of hospital care she received." Currently we have high pregnancy related mortality ratio (247 deaths due to any causes in pregnancy up to six weeks after pregnancy event per 100 thousand live births) and maternal mortality ratio (229 deaths due to pregnancy and childbirth related cause per 100 thousand live births) which constitutes $11 \%$ of deaths of women of reproductive age group.

Various associated risk factors contribute to near miss events. Commonly seen in our context are: Antepartum/Postpartum hemorrhage, complication of abortion, ruptured ectopic and ruptured uterus, Hypertension complicating pregnancy: severe preeclampsia, eclampsia, sepsis or severe systemic 
infection, provision of standard care: oxytocin infusion, provision of $\mathrm{MgSO}_{4}$, provision of antibiotics during caesarian, associated medical and surgical complication, presence of contributory factors: HIV, anemia, previous lower segment caesarian section, prolonged / obstructed labor .

In spite of the evidence-informed process that led the development of the WHO criteria for identifying women with life-threatening conditions, an actual validation of such criteria is required. In low-resource settings like in Nepal, application of these organ-failure based criteria that require relatively sophisticated laboratory and clinical monitoring can underestimate the occurrence of maternal near miss. Therefore, these criteria and the suggested WHO approach may not be able to identify maternal near miss across all settings appropriately. The threshold of five units of blood for identification of MNM according to WHO criteria led to underreporting of MNM in a low resource setting. ${ }^{4}$ Five factor scoring system uses 3 units of threshold of blood with specificity of $93.9 \% .^{5}$

The objective of this study was to evaluate the associated risk factors and determinants of near miss obstetric cases at B.P. Koirala institute of health sciences, a tertiary hospital in eastern Nepal, Dharan.

\section{METHODS}

This was a Prospective Observational Study done over 11 months from August 1, 2014 to June 30, 2015 in the Department of Obstetrics and Gynecology at BPKIHS hospital, tertiary care hospital in Eastern Nepal, Dharan.

Among the patient admitted under the care of department of obstetrics and gynecology, potentially all lifethreatening conditions were assessed, and those cases which met WHO criteria for near miss were given score as per Five factor scoring system and score of equal or more than 8 were enrolled in the study. Sample was taken on the basis of fulfillment of criteria.

Table 1: Five factor scoring system.

\begin{tabular}{|ll|}
\hline Factors & Score \\
\hline Organ - system failure & 5 \\
\hline ICU admission & 4 \\
\hline Transfusion $>3$ units, & 3 \\
\hline Extended intubation (>12 hour), & 2 \\
\hline $\begin{array}{l}\text { Surgical intervention (hysterectomy, } \\
\text { relaparotomy) }\end{array}$ & 1 \\
\hline
\end{tabular}

\section{Organ system failure (WHO: near-miss criteria)}

\section{Cardiovascular dysfunction}

- Shock,

- Cardiac arrest (absence of pulse/ heart beat and loss of consciousness),
- Use of continuous vasoactive drugs,

- Cardiopulmonary resuscitation,

- Severe hypoperfusion (lactate $>5 \mathrm{mmol} / \mathrm{l}$ or $>45$ $\mathrm{mg} / \mathrm{dl})$, severe acidosis $(\mathrm{pH}<7.1)$

\section{Respiratory dysfunction}

- Acute cyanosis,

- Gasping,

- Severe tachypnea (respiratory rate $>40$ breaths per minute),

- Severe bradypnea (respiratory rate $<6$ breaths per minute),

- Intubation and ventilation not related to anesthesia,

- $\quad$ severe hypoxemia (O2 saturation $<90 \%$ for $\geq 60$ minutes or $\mathrm{PAO} 2 / \mathrm{FiO} 2<200)$

\section{Renal dysfunction}

- Oliguria non-responsive to fluids or diuretics, dialysis for acute renal failure,

- Severe acute azotemia (creatinine $>300 \mu \mathrm{mol} / \mathrm{ml}$ or $>3.5 \mathrm{mg} / \mathrm{dl}$

\section{Coagulation/haematological dysfunction}

- Failure to form clots,

- Massive transfusion of blood or red cells (>5 units),

- Severe acute thrombocytopenia $\quad(<50 \quad 000$ platelets/ml)

\section{Hepatic dysfunction}

- Jaundice in the presence of pre-eclampsia,

- Severe acute hyperbilirubinemia (bilirubin >100 $\mu \mathrm{mol} / \mathrm{l}$ or $>6.0 \mathrm{mg} / \mathrm{dl})$

\section{Neurological dysfunction}

- $\quad$ Prolonged unconsciousness (lasting >12 hours)/coma (including metabolic coma),

- Stroke,

- Uncontrollable fits/status epilepticus,

- Total paralysis

\section{Uterine dysfunction}

- Uterine hemorrhage or infection leading to hysterectomy

Women with complication beyond 42 days of childbirth and non pregnant women with complications were excluded.

Data was entered into a computer database using Microsoft Excel spreadsheet and statistical analysis was performed. Results were presented as frequencies, percentages and descriptive statistics. 
Primary outcomes were to evaluate of the associated risk factors of the near miss events.

Secondary outcome was to calculate:

- $\quad$ MNM incidence ratio = maternal near miss cases per 1,000 livebirths (LB). MNMIR=MNM/LB.

- Maternal near miss: mortality ratio= Proportion between maternal near miss cases and maternal deaths. Higher ratio indicates better care.

- Mortality index=Number of maternal deaths divided by the number of women with life threatening conditions, expressed as a percentage.

- $\quad$ Severe maternal outcome ratio $(\mathrm{SMOR})=$ The number of women with life-threatening conditions (MNM + MD) per 1000 live births (LB).

\section{RESULTS}

A total of 9,727 deliveries were attended during the study period of 11 months from August 1, 2014 to June 30, 2015.

Table 2: Secondary outcomes.

\begin{tabular}{|lll|}
\hline Maternal near miss indicator & Indices & Range \\
\hline Maternal near miss & 162 & $0-46$ \\
\hline Live Birth, LB & 9,546 & $618-21543$ \\
\hline Maternal death & 16 & $0-9$ \\
\hline Severe maternal outcome rate & 18.64 & $2-16$ \\
\hline Near-Miss Rate, NMR & 16.6 & $1.4-16$ \\
\hline Mortality Index, MI & 0.089 & $0-0.45$ \\
\hline Near-miss per maternal death & $10.1: 1$ & $0-12: 1$ \\
\hline Maternal mortality ratio, MMR & 167 & $0-200$ \\
\hline
\end{tabular}

There were 6307 vaginal delivery (71.5\%) and 2777 $(28.5 \%)$ caesarean section and 181 perinatal death with total of 9,546 live birth. Total of 162 near miss were identified and 16 maternal death occurred during the study.

The study showed maternal near miss rate of 16.6 per 1000 livebirth and maternal mortality rate of 167 per 100000 livebirth. Women with life-threatening conditions (WLTC) of 172, Severe maternal outcome ratio of 18.64 per 1000 livebirth, Maternal near-miss mortality ratio (MNM: 1 MD) 10.1:1, Mortality index (MI) of $8.98 \%$.

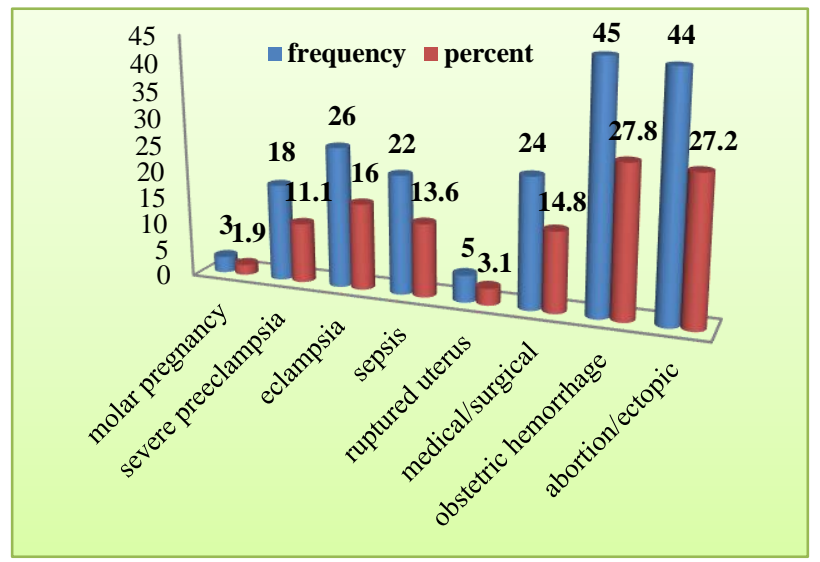

Figure 1: Prevalence of risk factors.

The study showed $27.8 \%$ had obstetric hemorrhage as the leading risk factor for the near miss, $27.2 \%$ was due to complication of abortion/ectopic, $27.1 \%$ of near miss was due to hypertensive disorder of pregnancy (eclampsia and preeclampsia), $14.8 \%$ with medical/surgical condition, followed by sepsis $13.6 \%$, then ruptured uterus $3.1 \%$, and least with molar pregnancy, i. e. $1.9 \%$.

Table 3: Organ dysfunction.

\begin{tabular}{|c|c|c|c|c|c|c|c|}
\hline \multirow{2}{*}{ Risk factor (no.) } & \multicolumn{7}{|c|}{ Organ dysfunction (\%) } \\
\hline & Cardioascular & Respiratory & Renal & Coagulation & Hepatic & Neurologic & Uterine \\
\hline Molar pregnancy (3) & $1(33.3)$ & $1(33.3)$ & - & $1(33.3)$ & - & - & - \\
\hline Severepreeclamsia (18) & $8(44.4)$ & $8(44.4)$ & $3(16.7)$ & $3(16.7)$ & - & - & - \\
\hline Eclampsia (26) & $5(19.2)$ & $12(46.2)$ & $9(34.6)$ & $4(15.4)$ & $3(11.5)$ & $2(7.7)$ & - \\
\hline Sepsis (22) & $11(50)$ & $8(36.4)$ & $6(27.3)$ & $3(13.6)$ & $3(13.6)$ & - & - \\
\hline Ruptured uterus (5) & $1(20)$ & $1(20)$ & - & - & - & - & $5(100)$ \\
\hline Surgical/medical (24) & $9(37.5)$ & $4(16.7)$ & - & $13(54.2)$ & $3(12.5)$ & - & - \\
\hline $\begin{array}{l}\text { Obstetric hemorrhage } \\
\text { (24) }\end{array}$ & $30(66.7)$ & $2(4.4)$ & $4(8.9)$ & $16(35.6)$ & $2(4.4)$ & - & $6(13.3)$ \\
\hline Ruptured ectopics (44) & $28(63.6)$ & $5(11.4)$ & $3(6.8)$ & $11(25)$ & $1(2.3)$ & - & - \\
\hline
\end{tabular}

Majority of risk factors had cardiovascular dysfunction as leading life-threatening condition. Hypertensive disorder had cardiovascular and respiratory dysfunction as a leading life-threatening condition. Among hemorrhagic patient cardiovascular dysfunction was followed by coagulation dysfunction.

$80 \%$ of the near miss patients were referred from other heath facility likewise $16.7 \%$ had laparotomy within 3 
hours of arrival, similarly who came themselves were $9.9 \%$ and $9.3 \%$ had delivery or abortion before arrival to the hospital.

Table 4 shows nearly $81 \%$ of near miss patient were referred from other health facilities and only $9.9 \%$ had arrived at the hospital without referral. Rest occurred during their stay at this hospital.

Table 5 shows $51.1 \%$ of obstetrics hemorrhagic cases were admitted to ICU, likewise, $95.6 \%$ of them received blood products and $71.1 \%$ of obstetrics hemorrhagic women were referred from other health facilities.

Table 4: Condition at arrival in the facility and the referral process $(\mathrm{N}=162)$.

\begin{tabular}{|ll|}
\hline Determination & Frequency \\
\hline $\begin{array}{l}\text { Delivery or abortion occurred before } \\
\text { arrival }\end{array}$ & $15(9.3 \%)$ \\
\hline Laparotomy within 3 hours of arrival & $27(16.7 \%)$ \\
\hline $\begin{array}{l}\text { Woman referred from other health } \\
\text { facility }\end{array}$ & $131(80.9 \%)$ \\
\hline Self & $16(9.9 \%)$ \\
\hline
\end{tabular}

Table 5: Obstetric hemorrhage and its intervention $(\mathrm{N}=\mathbf{4 5})$.

\begin{tabular}{|ll}
\hline Obstetric hemorrhage patients & Percentage \\
\hline ICU admission & 51.1 \\
\hline Use of blood products & 95.6 \\
\hline Women referred from other health facility & 71.1 \\
\hline
\end{tabular}

Table 6: Prevention of near miss obstetric hemorrhage $(\mathrm{N}=45)$.

\begin{tabular}{|lll|}
\hline Prevention & Frequency & Percentage \\
\hline Oxytocin & 38 & 84.4 \\
\hline Other Uterotonic & 10 & 22.2 \\
\hline Active management & 20 & 44.4 \\
\hline
\end{tabular}

Table 7: Treatment of near miss obstetric hemorrhage $(\mathrm{N}=45)$.

\begin{tabular}{|c|c|c|}
\hline Treatment & Frequency & Percentage \\
\hline Oxytocin & 30 & 66.7 \\
\hline Ergometrine & 8 & 17.8 \\
\hline Misoprostol & 25 & 55.6 \\
\hline Tranexamic Acid & 24 & 53.3 \\
\hline $\begin{array}{l}\text { Removal of retained } \\
\text { products }\end{array}$ & 7 & 15.6 \\
\hline $\begin{array}{l}\text { Balloon or condom } \\
\text { tamponade }\end{array}$ & 1 & 2.2 \\
\hline Hysterectomy & 7 & 15.6 \\
\hline Other uterotonics & 8 & 17.8 \\
\hline
\end{tabular}

From the Table 6 , we observe that $84.4 \%$ received Oxytocin for the prevention of obstetric hemorrhage, $22.2 \%$ received other uterotonic like methergin, misoprostol for the prevention and $44.4 \%$ had active management of third stage of labor.

Oxytocin was the major uterotonic used for the treatment of obstetric hemorrhage in $66.6 \%$ of cases, followed by misoprostol, $55.6 \%$ and tranexamic acid, 53.3\%. 7 patient underwent hysterectomy after failed medical management. One patient $(2.2 \%)$ received balloon/condom tampanode for the treatment of obstetric hemorrhage and $17.8 \%$ had other uterotonics as a treatment.

Table 8: Anticonvulsant magnesium sulfate (risk factor eclampsia).

\begin{tabular}{|ll|}
\hline Anticonvulsant & $\begin{array}{l}\text { Eclampsia } \\
\text { frequency }\end{array}$ \\
\hline Magnesium sulphate received & $23(92 \%)$ \\
\hline Magnesium sulphate not received & $2(8 \%)$ \\
Total & $25(100 \%)$ \\
\hline
\end{tabular}

From the Table 8, it shows that 23 (92\%) got anticonvulsant (magnesium sulphate) during their treatment and $2(8 \%)$ did not have.

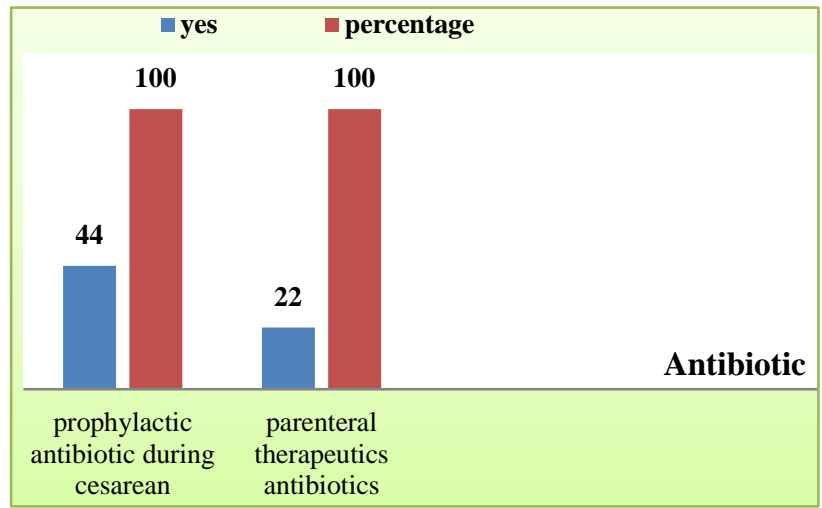

Figure 2: Prevention and treatment of infection and sepsis.

This study showed that $100 \%$ received prophylactic antibiotics before cesarean section and $100 \%$ received parenteral antibiotics therapeutically during the treatment of sepsis. This study had $44(27 \%)$ caesarean section, curettage $26(16 \%)$, laparotomy for ruptured ectopic 21 $(13 \%)$, laparotomy for ruptured uterus were $5(3.1 \%)$. The entire patient had received antibiotic prophylactically before the surgical procedure.

Table 9: Intensive care ( $\mathrm{N}=162)$.

\begin{tabular}{|ll|}
\hline Intensive care & Frequency \\
\hline Use of blood products & $110(67.9 \%)$ \\
\hline Dialysis & $7(4.3 \%)$ \\
\hline Laparotomy & $36(22.2 \%)$ \\
\hline Admission to ICU & $116(71.6 \%)$ \\
\hline
\end{tabular}


Total number of near miss patient using blood products were 110 i.e. (67.9\%), and those who underwent dialysis were 7 i.e. $(4.3 \%)$, likewise laparotomy was done for 36 i.e. $(22.2 \%)$, and 116 i.e. $(71.6 \%)$ had admission to ICU.

Anemia was associated with $19.8 \%$ of near miss patient. $5.6 \%$ of near miss patient were associated with prolonged/ obstructed labor and $3.1 \%$ of near miss had previous cesarean section as associated factors, none of the patient had HIV as associated factors.

Table 10: Associated factor ( $\mathrm{N}=162)$.

\begin{tabular}{|lll|}
\hline Associated factors & Frequency & Percentage \\
\hline No associated condition & 116 & 71.6 \\
\hline HIV & - & - \\
\hline Anemia & 32 & 19.8 \\
\hline Previous LSCS & 5 & 3.1 \\
\hline Prolonged/obstructed labor & 9 & 5.6 \\
\hline
\end{tabular}

$37 \%$ near miss pregnancy ended with vaginal delivery, $27 \%$ with caesarean section, likewise curettage $16 \%$, laparotomy for ruptured ectopic 13\%, laparotomy for ruptured uterus were $5 \%$ and the lowest was women discharged or still pregnant, i.e $3 \%$.

\section{Table 11: End of pregnancy $(\mathrm{N}=162)$.}

\begin{tabular}{|l|l|}
\hline End of pregnancy & Frequency \\
\hline Vaginal delivery & $61(37 \%)$ \\
\hline Cesarean section & $44(27 \%)$ \\
\hline Curettage & $26(16 \%)$ \\
\hline Laparotomy for ectopic pregnancy & $21(13 \%)$ \\
\hline Laparotomy for ruptured uterus & $5(3 \%)$ \\
\hline Women discharged or still pregnant & $5(3 \%)$ \\
\hline
\end{tabular}

\section{DISCUSSION}

In 2011, around 273,465 women died worldwide during pregnancy, childbirth or within 42 days after childbirth. ${ }^{6}$ the majority of these women die in low- income countries, and sub-Saharan Africa carries the highest burden, with a maternal mortality ratio (MMR) ranging between 169/100,000 live births in southern sub-Saharan Africa and 478/ 100,000 live births in west sub-Saharan Africa. ${ }^{6}$

The maternal mortality ratio (MMR) in Nepal decreased substantially between 1996 and 2006, from 539 to 281 deaths per 100,000 births (Ministry of Health and Population) [MOHP]. Improvements in maternal health services have been key in reducing the country's MMR. The health care services that a woman receives during pregnancy, childbirth, and the immediate postnatal period are important for the survival and well-being of both the mother and the child.

A total of 9,727 deliveries were attended during this study period from August 1, 2014, to June 30, 2015.
There were 6307 vaginal delivery (71.5\%) and 2777 (28.5\%) caesarean section and 181 perinatal death with a total of 9,546 live birth. Total of 162 near miss were identified and 16 maternal death occurred during the study. Maternal near miss rate (MNMR) of 16.6 per 1000 live birth and Maternal Mortality Rate (MMR) of 167 per 100000 live birth.

Studies done in the developing countries show the same trend of maternal near miss rate(MNMR) and vary from anywhere between 15-40/1000 live births. ${ }^{7}$

The maternal mortality ratio at our setup was $167 / 100000$ live births. The Brazilian study showed a mortality rate of 260/100000 live births. ${ }^{8-10}$ In other developing countries the maternal mortality ratios were in between $423 / 100000$ live births to $324 / 100000$ live births. ${ }^{11}$

In a prospective multicenter surveillance done in Kathmandu valley, there were 41,676 total live births, 157 maternal near-miss cases and 26 maternal deaths during a year of study in the 2012 at nine healthcare facilities with sentinel units with the near-miss rate of 3.8 per 1000 live births. ${ }^{12}$ Near miss rate was low as compared to this study.

\section{Risk factors}

This study showed obstetric hemorrhage as the leading risk factor for the near miss i.e. $27.8 \%$ followed by hypertensive disorder $27.6 \%$ (eclampsia and severe preeclampsia) followed by the complication of abortion/ectopic i.e. $27.2 \%$. Majority of the hemorrhagic patient are postpartum hemorrhage patient attributed to lack of blood product in the periphery.

A study by Shrestha et al in Kathmandu showed hemorrhage $41.66 \%$ and hypertensive disorder of the pregnancy $27.77 \%$ as leading risk factor for maternal near miss comparable with present study. ${ }^{9}$

A similar study done in Karnataka showed hemorrhage as the leading cause $(44.2 \%)$, followed by hypertensive disorders $(23.6 \%)$ and sepsis $(16.3 \%){ }^{13}$

Another study in lle Ife, Nigeria showed severe hemorrhage $(41.3 \%)$, hypertensive disorders in pregnancy $(37.3 \%)$, prolonged obstructed labor $(23 \%)$, septicemia $(8.6 \%)$ and severe anemia $(4.6 \%)$ were the direct causes of near miss and this study showed the cause of risk factor comparable with present study. ${ }^{14}$

\section{Organ dysfunction}

Those women who present with organ dysfunction are severely ill and are most likely to benefit from intensive monitoring and care in an ICU. Hence, a high proportion (e.g. Over 70\%) of women with severe maternal outcomes are expected to be admitted to an ICU. In this study, Cardiovascular dysfunction i.e. 79 (48.8\%) was the 
leading life-threatening condition among near miss patients followed by Coagulation dysfunction i.e. 44 (27.2\%), Respiratory dysfunction i.e. 39 (24.1\%), Renal dysfunction 18 (11.1\%), Hepatic dysfunction 8 (4.9\%) and least followed by neurologic dysfunction i.e. 4 $(2.5 \%)$.

Majority of near miss patient admitted in ICU had organ dysfunction, cardiorespiratory the leading organ dysfunction requiring ventilator support or continuous use of vasoactive drugs.

Coagulation dysfunctions were common among hemorrhagic patient owing to the transfusion of more than 5 pints of blood. Majority of the patient were postpartum hemorrhage, or ruptured ectopic pregnancy or incomplete abortion with severe blood loss or due to thrombocytopenia. Thrombocytopenia was either gestational or associated medical illness.

In a study done in Indonesia, vascular dysfunction was by far the most common organ dysfunction (77.7\%), followed by cardiac (5.1\%) and renal dysfunction $(4.5 \%) .{ }^{15}$

Uterine dysfunction (27\%) was the leading organ dysfunction followed by Hematologic. $22 \%$ followed by Cardiovascular $21 \%$ in a multicentre surveillance in Kathmandu. ${ }^{12}$ Another study done in Kathmandu in 2008 showed vascular dysfunction $16 \%$ as a major dysfunction. $^{9}$

\section{Standard of care and process indicator}

Oxytocin was the main uterotonic used both prophylactically and therapeutically. $\mathrm{MgSO}_{4}$ was used in all cases of eclampsia. All laparotomies were performed within three hours of arrival. $88.2 \%$ of the hemorrhagic patient received Oxytocin as a treatment. $11.7 \%$ of the hemorrhagic patient received other than Oxytocin as a treatment adjusting remaining patient either aborted or delivered before arrival. $80 \%$ of the hemorrhagic patient received Oxytocin prophylactically. $17.3 \%$ received prophylactic antibiotics and $84 \%$ received parenteral antibiotics among the near miss patient.

Study done in Kathmandu showed Oxytocin administered in $86 \%$ (104 in 121) for prevention and 76\% (92 in 121) for treatment of PPH. ${ }^{12}$

\section{Associated factors}

Anemia was associated with $19.8 \%$ of near miss patient. $5.6 \%$ of near miss patient were associated with prolonged/ obstructed labor and $3.1 \%$ of near miss had a previous cesarean section as associated factors, none of the patients had HIV as associated factors.

In African countries, anemia was one of the associated factors in near miss event, and anemia was likely due to the prevalence of malaria. In present context, anemia was likely due to nutritional or secondary to blood loss following antepartum /postpartum hemorrhage or due to the complication of ectopic or abortion.

Limitation of study was that the study was a prospective observational study done for a period of 11 months. The risk factors were predefined by WHO and were evaluated. Had the study been comparative case control study then risk factors of near miss could have been correctly identified in our setup. Although this study did not specifically address avoidable factors, it has nevertheless raised awareness of the shortcoming of the management of serious maternal illnesses.

\section{CONCLUSION}

Any pregnant woman can develop life threatening complications with little or no advance warning. All women need access to quality maternal health services that can diagnose and manage life-threatening complications. This study highlights obstetric hemorrhage as the most common serious obstetric complication leading to near-miss event followed by hypertension during pregnancy. Evaluation of associated risk factor can be the potential tool for reduction of maternal morbity and mortality in Nepal.

\section{Funding: No funding sources}

Conflict of interest: None declared

Ethical approval: The study was approved by the Institutional Ethics Committee

\section{REFERENCES}

1. Adeoye IA, Ijarotimi OO, Fatusi AO. What are the factors that interplay from normal pregnancy to near miss maternal morbidity in a Nigerian tertiary health care facility? Health Care Women Int. 2015;36(1):70-87.

2. Mantel GD, Buchmann E, Rees H, Pattinson RC. Severe acute maternal morbidity: a pilot study of a definition for a near-miss. Br J Obstet Gynecol. 1998;105(9):985-90.

3. Tuncalp O, Hindin MJ, Souza JP, Chou D, Say L. The prevalence of maternal near miss: a systematic review. BJOG. 2012;119(6):653-61.

4. Nelissen E, Mduma E, Broerse J, Ersdal H, EvjenOlsen B, van Roosmalen J, et al. Applicability of the WHO maternal near miss criteria in a low-resource setting. PloS one. 2013;8(4):e61248.

5. Geller SE, Rosenberg D, Cox S, Brown M, Simonson L, Kilpatrick S. A scoring system identified near-miss maternal morbidity during pregnancy. J Clin Epidemiol. 2004;57(7):716-20.

6. Lozano R, Wang H, Foreman KJ, Rajaratnam JK, Naghavi M, Marcus JR, et al. Progress towards Millennium Development Goals 4 and 5 on maternal and child mortality: an updated systematic analysis. Lancet (London, England). 2011;378(9797):1139-65. 
7. Lotufo FA, Parpinelli MA, Haddad SM, Surita FG, Cecatti JG. Applying the new concept of maternal near-miss in an intensive care unit. Clinics (Sao Paulo, Brazil). 2012;67(3):225-30.

8. Souza JP, Cecatti JG, Parpinelli MA, Serruya SJ, Amaral E. Appropriate criteria for identification of near-miss maternal morbidity in tertiary care facilities: a cross sectional study. BMC Pregnancy Childbirth. 2007;7:20.

9. Shrestha NS, Saha R, Karki C. Near miss maternal morbidity and maternal mortality at Kathmandu Medical College Teaching Hospital. KUMJ. 2010;8(30):222-6.

10. Cecatti JG, Souza JP, Parpinelli MA, de Sousa MH, Amaral E. Research on severe maternal morbidities and near-misses in Brazil: what we have learned. Reprod Health Matters. 2007;15(30):125-33.

11. Almerie Y, Almerie MQ, Matar HE, Shahrour Y, Al Chamat AA, Abdulsalam A. Obstetric near-miss and maternal mortality in maternity university hospital, Damascus, Syria: a retrospective study. BMC Pregnancy Childbirth. 2010;10:65.
12. Rana A, Baral G, Dangal G. Maternal near-miss: a multicenter surveillance in Kathmandu Valley. JNMA. 2013;52(190):299-304.

13. Ps R, Verma S, Rai L, Kumar P, Pai MV, Shetty J. "Near miss" obstetric events and maternal deaths in a tertiary care hospital: an audit. J Pregnancy. 2013;2013:393758.

14. Adeoye IA, Onayade AA, Fatusi AO. Incidence, determinants and perinatal outcomes of near miss maternal morbidity in Ile-Ife Nigeria: a prospective case control study. BMC Pregnancy Childbirth. 2013;13:93.

15. Adisasmita A, Deviany PE, Nandiaty F, Stanton C, Ronsmans C. Obstetric near miss and deaths in public and private hospitals in Indonesia. BMC Pregnancy Childbirth. 2008;8:10.

Cite this article as: Khadka M, Uprety DK, Rai R. Evaluation of associated risk factors of near miss obstetrics cases at B.P. Koirala Institute of Health Sciences, Dharan, Nepal. Int J Reprod Contracept Obstet Gynecol 2018;7:xxx-Xx. 